\title{
Peran 'Aisyiyah Pekanbaru dalam Pengembangan Pendidikan di Kota Pekanbaru (1975-2015)
}

\author{
The Role of 'Aisyiyah Pekanbaru in Education Development in The City of \\ Pekanbaru (1975-2015) \\ Duwi Kartika $^{1 \bowtie}$, Bunari $^{2}$, Ahmal $^{3}$ \\ $1 \bowtie 23$ Universitas Riau

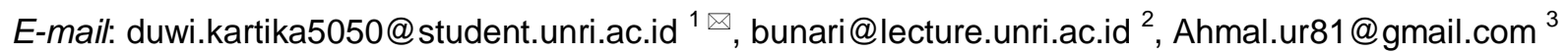

Diterima: 25 Oktober 2021 | Direvisi: 28 November 2021 | Diterbitkan: 29 November 2021

ARTICLE INFO

Keywords:

Aisyiah,

Pekan Baru,

Education development.

\section{Kata Kunci:}

Aisyiah,

Pekan Baru,

Pengembangan Pendidikan.
ABSTRACT

This study aims to analyze the role of Aisyiyah in the development of education in Pekanbaru City in 1975-2015, so as to find out the background of the establishment of Aisyiyah Pekanbaru. Aisyiyah as a special Autonomy organization for Muhammadiyah can foster women to be educated to become leaders, and be prepared to become administrators in Muhammadiyah women's organizations. Aisyiyah's presence in developing her educational role in Riau Province, especially in Pekanbaru City has produced strong cadres in organizing. Aisyiyah's presence in Pekanbaru is inseparable from the arrival of Muhammadiyah's understanding and thoughts. Aisyiyah is engaged in social, educational, health and religious fields. This research uses historical methods consisting of heuristics, verification, interpretation, historiography. Aisyiyah has activities with several programs, one of which is in the field of education, especially in Kindergarten (TK) Bustanul Athfal Aisyiyah, a program on worship that is guided by the Central Leadership (PP) in Jakarta on Kemuhammadiyahan and Keaisyiyahan. Based on the results of the study, it can be concluded: The presence of 'Aisyiyah in Pekanbaru is inseparable from the arrival of Muhammadiyah's understanding and thoughts. The entry of the notion of renewal (Muhammadiyah) to Pekanbaru is the establishment of da'wah and trade interactions with the surrounding area. Aisyiyah in education is concerned with Islamic children's education, providing formal and non-formal education with noble character.

Penelitian ini bertujuan untuk menganalisis peran Aisyiyah dalam pengembangan pendidikan di Kota Pekanbaru tahun 1975-2015, sehingga dapat mengetahui latarbelakang berdirinya Aisyiyah Pekanbaru. Aisyiyah sebagai organisasi Otonomi khusus Muhammadiyah dapat membina kaum perempuan untuk di didik menjadi pimpinan, serta dipersiapkan untuk menjadi pengurus dalam organisasi perempuan Muhammadiyah. Kehadiran Aisyiyah dalam mengembangkan peran pendidikannya di Provinsi Riau terkhususnya di Kota Pekanbaru telah melahirkan kader-kader yang tangguh dalam berorganisasi. Kehadiran Aisyiyah di Pekanbaru tidak terlepas dari kedatangan paham dan pemikiran Muhammadiyah. Aisyiyah bergerak dalam ranah sosial, pendidikan, kesehatan dan keagamaan, Penelitian ini menggunakan metode sejarah yang terdiri atas heuristik, verifikasi, intepretasi, Historiografi. Aisyiyah mempunyai kegiatan dengan beberapa program salah satu di bidang pendidikan terutama di Taman Kanak-kanak (TK) Bustanul Athfal Aisyiyah program mengenai ibadah yang di tuntun dari Pimpinan Pusat (PP) di Jakarta tentang Kemuhammadiyahan dan Keaisyiyahan. Berdasarkan 
hasil penelitian dapat disimpulkan: Kehadiran 'Aisyiyah di Pekanbaru tidak terlepas dari kedatangan paham dan pemikiran Muhammadiyah. Masuknya paham pembaharuan (Muhammadiyah) ke Pekanbaru ini terjalinnya interaksi dakwah dan perdagangan dengan daerah sekitar. Aisyiyah dalam pendidikan konsen terhadap pendidikan anak yang Islami, mberikan pendidikan formal dan non-formal yang berakhlak mulia.

\section{PENDAHULUAN}

Kehadiran Aisyiyah dalam mengembangkan peran pendidikannya di Provinsi Riau terkhususnya di Kota Pekanbaru telah melahirkan kader-kader yang tangguh dalam berorganisasi. Semangat berdirinya Muhammadiyah telah mengilhami hamoir seluruh ortom yang ada di Muhammadiyah, termasuk Aisyiyah. Dalam sejarah dan peta gerakan wanita Indonesia, Aisyiyah menempati posisi yang istimewa, dikarenakan Aisyiyah merupakan organisasi sosial-keagamaan tertua yang sampai sekarang masih aktif dan berkembang menjadi gerakan wanita modern dengan karakter sosial religiunya yang kuat (Seniwati \& Lestari, 2019).

Keberhasilan Aisyiyah dalam membangun modal sosial (social kapital) begitu banyak, salah satunya berupa amal usaha yang tersebar di penjuru Indonesia dengan struktur lembaga yang terorganisir secara menyeluruh. Hal ini pula yang menjadi salah satu dasar mengapa Aisyah mampu mempertahankan eksistensinya sampai masa sekarang sebagai gerakan perempuan Muhammadiyah yang berlandaskan visi mulia. Dalam pergerakannya juga Aisyah dapat dikatakan seimbang dengan gerakan kaum laki-laki Muhammadiyah, sehingga membedakannya dengan organisasi otonomi milik Muhammadiyah yang lain (Pajaitan, 2013).

Dibidang pendidikan Aisyiyah telah memiliki amal usaha pendidikan mulai dari tingkat TK/PAUD sampai dengan Perguruan Tinggi yang tersebar di seluruh Indonesia. Dibidang pendidikan, khususnya pendidikan anak usia dini jalur nonformal di Pekanbaru cukup mengembirakan. Pendidikan nonformal yang diselenggarakan Aisyiyah yaitu pendidikan AlIslam, Kemuhammadiyahan dan Keaisyiyahan. Sesuai dengan buku pedoman bahan ajar AIK (Al-Islam dan Kemuhammadiyahan) yang dikeluarkan oleh Majleis Dikdasmen PP Aisyiyah (pengembangan Al-Islam Taman Kanak-kanak Aisyiyah Bustanul Athfal, PP Aisyiyah bagian Dikdasmen Jakarta (Herlinda \& Afdal, 2020).

Seiring dengan perkembangan pendidikan Aisyiyah ditingkat provinsi Riau, pimpinan wilayah Aisyiyah Riau telah mendirikan STKIP 'Aisyiyah Riau di bumi lancang kuning pimpinan wilayah Aisyiyah Riau telah mendirikan STKIP 'Aisyiyah Riau di bumi lancang kuning Kampus STKIP Aisyiyah Riau yang merupakan kampus yang berdiri di atas tanah hak milik sendiri (yakni persyarikatan Muhammadiyah). Hal ini dapat menjadi salah satu perguruan tinggi yang memberikan pendidikan dan menjamin kualitas pendidikan bagi putra putri yang melanjutkan pendidikan di perguruan tinggi, terutama di bidang tenaga pendidik (Nurhayati, Yanzi, \& Nurmalisa, 2015)..

Daerah pendidikan Aisyiyah salah satunya berada di PDA Kota Pekanbaru Provinsi Riau yakni TK Aisyiyah Bustanul Athfaal (ABA) yang terdapat di berbagai tingkat cabang atau kecamatan yang ada di Pekanbaru. Dengan demikian, penelitian yang akan dilakukan 
Kartika, Bunari \& Ahmal, 2021, Peran `Aisyiyah Pekanbaru ...

merupakan kajian atau perkembangan dari penelitian sebelumnya, sehingga dapat terlihat jelas bahwa kajian yang sedang dilakukan bukan merupakan pengulangan atau duplikasi. Berdasarkan yang sudah dilakukan terhadap beberapa sumber kepustakaan, penulis belum menemukan skripsi tentang "Peran 'Aisyiyah Pekanbaru dalam Pengembangan Pendidikan di Kota Pekanbaru (1975-2015)".

Berikut beberapa penelitian yang relevan dengan penelitian ini adalah: Pertama tulisan Elsa Risty Fauzia tentang "Peranan Pimpinan Daerah Aisyiyah Kabupaten Buol dalam Meningkatkan Pendidikan Anak" membahas tentang (1) Cara inovatif yang digunakan pimpinan Aisyiyah Kabupaten Buol untuk memajukan pendidikan anak. Program yang disusun ketika rapat kerja oleh Pimpinan Daerah Aisyiyah Kabupaten Buol beserta para anggota memberikan sumbangsih yang baik. Akan tetapi tidak semua program yang tersusun dapat dilaksanakan dengan baik karena sering terdapat hambatan yang tidak terduga, namun tidak dapat dipungkiri bahwa kegiatan yang dilaksanakan terus mengalami progresifitas. (2) Hasil yang kurang maksimal dalam pelaksanaan kegiatan tersebut, di latarbelakangi karena beberapa hal, diantaranya yaitu kurangnya kerjasama antar pengurus serta tidak ada keseimbangan antara pendidikan formal dan non formal.

Kedua tulisan Tri Mulyani "Peranan Aisyiyah dalam Pemberdayaan Pendidikan di Tinggarjaya Tahun 1935-2016" membahas tentang (1) Pimpinan cabang 'Aisyiyah Jatilawang berdiri tanggal 21 April 1935, berawal dari pendirian PKU oleh Muhammadiyah di Tinggarjaya yang membutuhkan sosok perempuan sebagai ibu untuk merawat anak yatim di panti asuhan, (2) Amal usaha 'Aisyiyah terdiri dari amal usaha di bidang ekonomi, sosial, pendidikan, kesehatan, kader, dan tabligh. Amal usaha yang punya konstribusi besar ialah amal usaha pendidikan, (3) 'Aisyiyah cabang Jatilawang mampu mengembangkan pendidikan disana, dengan bukti bertambahnya sekolah yang ada di Tinggajaya.

Ketiga tulisan Syarifuddin "Peran Ranting 'Aisyiyah dalam Pendidikan Islam di Karangasem Laweyan Surakarta Tahun 20052010" membahas tentang peran dari ranting 'Aisyiyah Karangasem di dunia pendidikan. Proses pengembangannya yang dilakukan ranting Karangasem meliputi berbagai tiga aspek pendidikan yaitu: pendidikan formal, non formal dan informal. Selama proses pengembangannya ranting ini memiliki berbagai macam hambatan, walaupun begitu ranting ini terus mengalami kemajuan dalam memberdayakan pendidikan di sana.

Keempat tulisan Syifaul Wahid "Peranan Cabang Muhammadiyah dalam Pengembangan Pendidikan Islam (Studi Empiris Pimpinan Cabang Muhammadiyah Colomadu Karanganyar Tahun 2010-2015)" membahas tentang konstribusi Muhammadiyah dalam pendidika Islam yang mencakup pendidikan formal, non formal dan informal. Pada aspek formal konstribusi yang diberikan antara lain: memberikan kurikulum keislaman sesuai dengan mata pelajaran agama Islam serta memberikan arahan serta nasihat agar para siswa menjauhi hal-hal yang mengandung unsur negatif. Dalam pendidikan non forma, peran yang terlihat adalah, memberikan dakwah materi keislaman sebagai bekal pedoman hidup. Selain 
itu juga dilaksanakannya kajian dan pengajian yang bertujuan untuk memperbaiki akhlak yang dimiliki oleh setiap individu. Terakhir pada kegiatan informal, Muhammadiyah melaksanakan kegiatan sosial di masyarakat serta menanamkan nilai kebhinekaan dan kasih sayang dalam berbangsa dan beragama.

Kelima tulisan Nuryanti "Sejarah Organisasi Muahammadiyah dalam Kontribusi Bidang pendidikan di Kabupaten Kendal" membahas tentang sejarah organiasasi Muhammadiyah di Kabupaten Kendal. Tulisan ini membahas tentang sejarah dan asal-usul Muhammadiyah di Kabupaten Kendal, serta bagaimana organisasi ini dapat mempertahankan eksistensinya disana dengan sistemnya yang berdiri sendiri. Dalam artikel ini juga turut di ulas pengaruh besar yang diciptakan oleh Muhammadiyah sampai saat ini yang tidak terlepas dari dukungan para kader yang sentiasa luar biasa dan begitu ulet dalam pergerakannya.

Kemudian artikel ini di tutup dengan kajian peran organisasi Muhammadiyah di sektor pendidikan yang terus memberikan konstribusi pada setiap zaman dan selalu mengikuti kemajuan tidak stag pada proses yang lama. Hal ini karena Muhammadiyah berhasil mengelola struktur organisasinya dengan baik. Lebih jauh keberhasilan pengembangan sektor pendidikan ini terlihat jelas dari kemampuan daya serap setiap sekolah Muhammadiyah terhadap lingkungan sekitar. Sehingga dalam hal ini sekolah Muhammadiyah mempunyai peranan sosial yang menyeluruh dan berdampak terhadap lingkungan sekitar.

Peran merupakan sebuah landasan presepsi yang digunakan setiap orang yang berinteraksi dalam suatu kelompok atau organisasi untuk melakukan suatu kegiatan mengenai tugas dan kewajiban. Menurut Soekanto (2004) peranan merupakan suatu aspek yang dinamis dari suatu kedudukan atau status. Apabila seseoarang melaksanakan hak dan kewajibannya sesuai dengan kedudukannya maka dia akan menjalankan suatu peranan. Setiap orang memiliki berbagai macam peranan yang berasal dari pola-pola pergaulan hidup. Hal tersebut sekaligus berarti bahwa peranan menentukan apa yang diperbuatnya bagi masyarakat kepadanya. Organisasi Aisyiyah merupakan sebuah gerakan perempuan yang lahir di Yogyakarta pada 1917. Aisyiyah didirikan oleh KH. Ahmad Dahlan dan Nyai Ahmad Dahlan. Sejak pendiriannya pada 1917, tujuan utama Aisyiyah adalah menumbuhkan kesadaran masyarakat, khususnya perempuan, terhadap berbagai masalah yang ada di masyarakat (Rof'ah, 2016). Aisyiyah merupakan organisasi perempuan di bawah payung Persyarikatan Muhammadiyah yang menyebarkan kebaikan dan dakwah Islam dengan fondasi dasar amar ma'ruf nahi munkar dan tajdid, yang bersumber kepada Al-Qur'an dan As-Sunnah (Efendi, 2008).

Pendidikan 'Aisiyah bertujuan untuk melahirkan cendikiawan-cendikiawan muslim yang memiliki keseimbangan antara pengetahuan umum dan ilmu agama, sehingga selalu memegang teguh syariat Islam, berakhlak mulia serta cerdas. Aisyiyah sebagai organisasi perempuan memiliki beberapa program untuk meningkatkan kegiatannya di bidang pendidikan yaitu pendidikan formal, nonformal dan informal. Salah satu program tersebut, yakni pendidikan 
Kartika, Bunari \& Ahmal, 2021, Peran `Aisyiyah Pekanbaru ...

al-Islam dan kemuhammadiyahan. Program ini tidak hanya diterapkan dalam Aisyiyah saja melainkan kepada semua bidang organiasi Muhammadiyah yang lain. Program ini merupakan bentuk ajaran keislaman yang bersumber pada al-Qur'an dan Sunnah Nabi Muhammadd Shalallahu Alaihi Wassalam. Pendidikan al-Islam dan kemuhammadiyahan dilaksanakan demi mengajarkan, menanamkan, serta mengimplementasikan nilai-nilai ajaran Islam dalam kehidupan sehari-hari.

\section{METODE}

Metode adalah suatu cara yang dilaksanakan seseorang secara teratur dalam tercapai suatu tujuan. Metode itu sendiri berarti cara, jalan, atau petunjuk pelaksanaan atau petunujk teknis (Abdurahman, 2007). Metode yang penulis gunakan dalam penelitian ini adalah metode Sejarah. Metode sejarah merupakan cara untuk mengkaji suatu peristiwa, tokoh atau permasalahan yang dianggap layak dan penting yang terjadi pada masa lampau secara deskriptif, kritis dan analitis. Dalam metode sejarah terdapat empat langkah-langkah, yaitu:

1. Heuristik

Heuristik merupakan sebuah kegiatan mencari sumber-sumber untuk mendapatakan data-data, baik berupa sumber tulisan maupun sumber lisan atau meteri sejarah yang berhubungan dengan permasalahan yang akan dikaji oleh penulis.

2. Verifikasi

Verifikasi adalah kegiatan dalam penelitian sejarah yang dilakukan dengan cara memeriksa, mengkoreksi, dan menilai sumber-sumber sejarah yang telah dikumpulkan. Bahan-bahan maupun informasi yang dikumpulkan ketika melakukan pengujian terhadap kebenaran yang didapat sehingga menghasilkan sebuah penelitian yang objektif.

3. Intepretasi

Interpretasi adalah menafsirkan fakta sejarah dan merangkai fakta tersebut hingga menjadi satu kesatuan yang harmonis dan masuk akal. Dari berbagai fakta yang ada. Kemudian perlu disusun agar mempunyai bentuk dan struktur. Dalam tahap ini peneliti membuat deskripsi, analisis kritis serta pemilihan fakta dan data kemudian disusun, ditafsirkan, dan dikorelasikan satu dengan lainnya sehingga menjadi suatu kesatuan yang logis dan rasional serta memiliki makna sehingga dapat digunakan dalam penulisan sejarah yang baik.

4. Historiografi

Fase terakhir dalam metode sejarah adalah historiografi. Historiogrfi merupakan cara penulisan, pemaparan atau pelaporan hasil penelitian sejarah yang telah dilakukan. Layaknya laporan penelitian ilmiah, penulisan hasil penelitian sejarah hendaknya dapat memberi gambaran yang jelas mengenai proses penelitian dari awal (fase perencanaan) sampai dengan akhir (penarikan kesimpulan) (Abdurahman, 2007).

\section{HASIL DAN PEMBAHASAN}

Pekanbaru yang dikenal sekarang, pada awalnya termasuk bagian dari Kerajaan Siak Sri Indrapura. Sebagian besar wilayahnya dahulu berada dipinggiran Sungai Siak, yang lebih dikenal dengan Senapelan. Kepercayaan masyarakat Pekanbaru melekat dengan Islam sebagaimana dipahami dan diamalkan oleh 
masyarakat Siak, yaitu berpaham kaum tua (tradisional). Salah satu ciri khas kaum tradisional adalah berpegang teguh pada tradisi turun-temurun dan sulit menerima hal-hal yang berkaitan dengan pembaharuan. Kehadiran Aisyiyah di Pekanbaru tidak terlepas dari kedatangan paham dan pemikiran Muhammadiyah. Berdirinya Aisyiyah di Pekanbaru diawali dengan gerakan Aisyiyah yang dimotori oleh ibu Janewar Saleh seperti wirid-wirid pengajian.

Organisasi Aisyiyah merupakan organisasi otonomi khusus Muhammadiyah. Islam yang berkemajuan sebagaimana yang terlihat dari penafsiran Muhammadiyah-Aisyiyah terhadap ayat-ayat al-Qur'an yang tidak membedakan jenis kelamin dalam hal berdakwah, menjadi karakter gerakan Muhammadiyah-Aisyiyah. Paham Islam berkemajuan dan pentingnya pendidikan bagi gerakan MuhammadiyahAisyiyah menghasilkan pemebaharuanpembaharuan jenis-jenis kegiatan yang dilakukan Muhammadiyah-Aisyiah, seperti merintis berdirinya pendidikan untuk anak usia dini, yang saat ini bernama TK 'Aisyiyah Bustanul Athfal (TK ABA). Kantor PDA Kota Pekanbaru sejak awal berdiri sampai sekarang berada di jalan K.H Ahmad Dahlan Sukajadi Kota Pekanbaru (Fadlillah, Kristiana, \& Fadhli, 2020).

Aisyiyah sebagai organisasi memerlukan adanya struktur organisasi. Struktur organisasi Aisyiyah dibentuk sama seperti struktur organisasi Muhammadiyah, yang terdiri atas bidang kegiatan amal usaha. Periodesasi kepemimpinan PDA Kota Pekanbaru sejak didirikannya hingga sekarang, di antaranya sebagai berikut:

Tabel 1. Susunan Pimpinan Daerah 'Aisyiyah Pekanbaru mulai 1975-2015

\begin{tabular}{ccc}
\hline No & $\begin{array}{c}\text { Tahun Periode } \\
\text { Kepemimpinan }\end{array}$ & Ketua \\
\hline 1 & $1975-1980$ & Nurani Yapin \\
\hline 2 & $1980-1985$ & Janewar Saleh \\
\hline 3 & $1985-1990$ & Yuliar Noor \\
\hline 4 & $1990-1995$ & Yuliar Noor \\
\hline 5 & $1995-2000$ & $\begin{array}{c}\text { Emma Yunisma } \\
\text { Rusmoyo }\end{array}$ \\
\hline 6 & $2000-2005$ & Yulia Iriani \\
\hline 7 & $2005-2010$ & Midawati \\
\hline 8 & $2010-2015$ & Midawati \\
\hline
\end{tabular}

Kegiatan didalam Aisyiyah sama dengan Muhammadiyah yang bergerak di bidang tabligh, ekonomi, kesehatan, pendidikan, pembinaan pengkaderan dan kesejahteraan sosial. Persyarikatan Aisyiyah cenderung mengelolah pendidikan anak usia dini, dari usia dini sesuai dengan cabang masing-masing yang berada di Kota Pekanbaru. Aisyiyah berkiprah di Kota Pekanbaru memberikan pendidikan islami begitupun yang diseluruh Indonesia. Berdirinya TK Aisyiyah I di Kota Pekanbaru pada tahun 1959 merupakan bentuk pergerakan awal amal usaha Aisyiyah di Pekanbaru. Program pembelajaran Aisyiyah perpaduan antara pembelejaran islam dan umum, pembelajaran TK bidang pengembangan dari Dinas Pendidikan ditambah dengan pengembangan bidang materi Al-Islam, Keaisyiyahan dan Kemuhammadiyahan yang dipadukan dalam pembelajaran (Fadlillah et al., 2020).

Pembelajaran Al-Islam yaitu belajar bacaan shalat, hafalan ayat-ayat pendek sesuai dengan 
Kartika, Bunari \& Ahmal, 2021, Peran `Aisyiyah Pekanbaru ...

tarjih Muhammadiyah-Aisyiyah. Berdirinya Aisyiyah Pekanbaru ditandai dengan awal berdirinya pembangunan TK Aisyiyah I pada tahun 1959. Aisyiyah Pekanbaru dalam pengembangan pendidikan dilihat dari bertambahnya jumlah pembangunan sekolah TK Aisyiyah Kota Pekanbaru yang saat ini berjumlah 13 sekolah, 2 diantara sekolah TK Aisyiyah saat ini non-aktif. Untuk pembelajaran umum TK Aisyiyah sesuai dengan yang diberikan Dinas pendidikan dalam bidang pengembangannya yaitu: moral agama, seni, bahasa, kognitif dan motorik semuadikombinasikan antara pemebelajaran Islam, Aisyiyah Keaisyiyahan. Pada tahun 31 Januari 1992 PDA Pekanbaru mendirikan Ikatan Guru Bustanul Athfal (IGB) pada masa pimpinan Aisyiyah periode 1995-2000. IGB diganti menjadi IGABA (Ikatan Guru Busthanul Athfal) ditahun 2005 ini sebagai wadah guru-guru Aisyiyah Bustanul Athfal (ABA) dalam perkumpulan guru Aisyiyah. IGABA ini selalu diisi pertemuan dalam upaya untuk meningkatkan profesi guru. Mewujudkan organisasi wanita Islami yang berkemajuan, Aisyiyah memberikan pendidikan kaderisasi Muhammadiyah-Aisyiyah dalam pelatihan Baitul Arqom (Jannah, 2013).

Baitul Arqom adalah pengkaderan dari organisasi Muhammadiyah-Aisyiyah. Program ini menjalani penginapan dua hari, dalam hal ini mengkaji materi-materi tentang bagaimana Islam yang sebenarnya. Bertujuan untuk menciptakan kesamaan dan kesatuan sikap, integritas, wawasan dan cara berpikir dikalangan persyarikatan dan amal usaha Muhammadiyah. Dalam sistem perkaderan Aisyiyah melalui perkaderan informal, perkaderan formal, nonformal dan perkadran khsus. Perkaderan informal merupakan sebuah kegiatan perkaderan yang dilakukan secara tidak resmi dalam suatu interaksi kehidupan anggota, pimpinan maupun kader, tanpa adanya perencanaan sistematik, baik kurikulum, metode, waktu dan tempat (Salman, 1995).

Pelatihan perkaderan formal ialah sebuah bentuk perkaderan yang dilakukan melalui pelatihan-pelatihan dalam berbagaimacam bentuk dan jenis kegiatan yang disebut: Baitul Arqom Aisyiyah, TOT Baitul Arqom, dan pelatihan khusus yang dilaksanakan oleh pimpinan organisasi, majelis maupun lembaga.

Perkaderan non formal adalah kegiatan perkaderan yang dilaksanakan secara terprogram diluar kegiatan pelatihan. Adapun bentuk perkaderan nono formal antara lain: penataran pimpinan, penyegaran atau revitalisasi pimpinan, kegiatan ideopolitor, pengajian ramadhan dan pengkajian khusus mendalami ideologi Muhammadiyah dan nilainilai perjuangan Aisyiyah (Kartini, 2017). Tujuan Aisyiyah adalah membentuk intelektul yang memiliki kepribadian muslim yang mampu menyeimbangkan antara kepandaian ilmu yang dimilikinya dengan akhlak dan agamanya. Berdirinya panti asuhan putri Aisyiyah adalah menginginkan para putri-putri agar dapat tumbuh dan berkembang secara wajar baik rohani, jasmani dan sosial yang berakhlak mulia. Amal usaha Aisyiyah dalam pengembangan pendidikan diterapakan juga di panti asuhan putri Aisyiyah Pekanbaru yang memberikan pendidikan formal, nonformal, peleyanan kesehatan, sandang pangan, dan fasilitas lain. Selain menerima anak yatim piatu, panti asuhan putri Aisyiyah juga membantu pendidikan anak- 
anak yang kurang mampu dalam ekonomi keluarga (kaum dhuafa) dengan mengikuti persayaratan yang diberikan panti asuhan puti Aisyiyah Pekanbaru (Fadlillah et al., 2020).

Selain mendapat pendidikan formal anak asuh juga mendapatkan pendidikan dari segi kemandirian, Akhlak, etika, moral dan budi pekerti yang baik. Tujuan berdirinya panti asuhan putri Aisyiyah adalah menginginkan para putri-putri agar dapat tumbuh dan berkembang secara wajar baik rohani, jasmani dan sosial yang berakhlak mulia. Dalam upaya mengembangankan pendidikan Aisyiyah meningkatkan kuantitas dan kualitas Aisyiyah yang ditanamkan dari usia dini sudah diperkenalkan tentang kemuhammadiyahankeaisyiyahan dalam pembelajaran Islam dan memeperkenalkan organisasi persyarikatan. Kiprah Aisyiyah di bumi lancang kuning ini memebantu pemerintah Kota Pekanbaru dan masyarakat dengan adanya pendidikan dari mulai tingkat TK Aisyiyah, bahkan sampai ditingkat wilayah sudah memiliki STKIP Aisyiyah Riau dengan tujuan untuk meningkatkan Sumber Daya Manusia (SDM).

\section{KESIMPULAN}

Aisyiyah Pekanbaru dalam perkembangan pendidikan dilihat dari bertambahnya sekolah TK Aisyiyah di Pekanbaru yang saat ini sudah berjumlah 13 TK. Dalam upaya mengembangkan pendidikan Aisyiyah meningkatkan kuantitas dan kualitas Aisyiyah yang ditanamkan dari usia dini sudah tentang kemuhammadiyahan-keaisyiyahan dalam mengajarkan pemebelajaran Islam dan memperkenalkan organisasi Muhammadiyah-
Aisyiyah semenjak dari pendidikan anak usia dini. Kiprah Aisyiyah di bumi lancang kuning ini membantu pemerintah Kota Pekanbaru dan masyarakat dengan terbuktinya dari mulai pendidrian TK Aisyiyah I Pekanbaru pada tahun 1959, bahkan ditingkat wilayah Aisyiyah sudah memiliki STKIP Aisyiyah Riau dengan tujuan untuk meningkatkan Sumber Daya Manusia (SDM).

Dalam beberapa wawanacara dengan masyarakat dilingkungan Muhammadiyah di sekitaran Sukajadi Kota Pekanbaru mengungkapkan bahwa respon masyarakat dengan masuknya Muhammadiyah-Aisyiyah terbukti dengan banyaknya anak-anak dimasukkan ke TK ABA karena masyarakat tertarik dengan pendidikan agama Islam yang kuat dari sekolah-sekolah MuhammadiyahAisyiyah. Pandangan masayarakat Secara organisasi Aisyiyah dapat diterima sebagai bagian dari Muhammadiyah yang telah berkontribusi dalam pendidikan di Kota Pekanbaru. Hanya saja, kebudayaan masayarakat Pekanbaru cenderung berjarak ideologis dengan Muhammadiyah.

\section{DAFTAR PUSTAKA}

Abdurahman, D. (2007). Metodologi Penelitian Sejarah. Yogyakarta: Ar-ruzz Media.

Efendi, A. (2008). Peran Strategis Lembaga Pendidikan Berbasis Islam di Indonesia. ElTarbawi, 1(1), 1-11. https://doi.org/10.20885/tarbawi.vol1 .iss 1.art1

Fadlillah, M., Kristiana, D., \& Fadhli, M. (2020). Pendidikan Al-Islam dan Kemuhammadiyahan pada Anak Usia Dini di Bustanul Athfal Aisyiah Ponorogo. Jurnal Obsesi: Jurnal Pendidikan Anak Usia Dini, 4(1), 406-417. https://doi.org/10.31004/obsesi.v4i1.362 
Herlinda, S., \& Afdal, Z. (2020). Pemantapan Pembelajaran Aik pada Guru Guru Tk Aisyiyah Sekota Pekanbaru. Dedikasi: Jurnal Pengabdian Dan Pemberdayaan Masyarakat, 1(1), 13-18. Retrieved from http://ejournal.stkipaisyiyahriau.ac.id/index.ph p/Dedikasi/article/view/227

Jannah, F. (2013). Pendidikan Islam dalam Sistem Pendidikan Nasional. Dinamika IImu, 13(2), 161-173. https://doi.org/10.32678/alqalam.v19i95.460

Kartini, N. H. (2017). Evaluasi Program Baitul Arqam bagi Karyawan di Universitas Muhammadiyah Palangkaraya. Anterior Jurnal, 16(2), 144-157.

Nurhayati, Yanzi, H., \& Nurmalisa, Y. (2015). Peran Lembaga Sosial terhadap Pembinaan Moral Remaja di Desa Bangunrejo. Jurnal Kultur Demokrasi, 4(1).

Pajaitan, H. (2013). Peran 'Aisyiyah dalam Pendidikan Islam. Medan: IAIN Sumatra Utara.

Salman, I. (1995). Peran Organisasi Aisyiyah dalam Mewujudan Keluarga Sakinah di Kalanga Angota. Jakarta: Universitas Indonesia.

Seniwati, \& Lestari, T. D. (2019). Sikap Wanita Muslim Kauman: Kajian Peranan Aisyiyah dalam mengembangkan Wanita di Yogyakarta pada tahun 1914-1925. Jurnal Walasuji, 10(2), 219-232. https://doi.org/https://dx.doi.org/10.36869/wjs b.v10i2.11 